\title{
3) $\mathfrak{x} \mathfrak{m} \mathfrak{a}$
}

$\infty$ (hon längere Zeit, feit Jahren, arbeite id) an einem

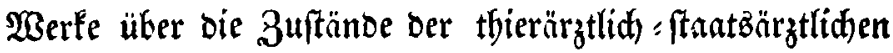

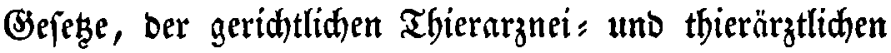
Polizeilunde in Deutifhland, und bie endidhe $\mathfrak{B e r b e f f e : ~}$ rung biefer 3uftänbe; bod) geftatteten die bamit verbun: Denen Gawierigfeiten bie Beendigung Deffelben biz jest nod) nidyt. Die Dringlifhleit Der Safbe, befonberż nes gen Desె jeb̧t wieber verfammelten 3ollcongreffes, veran: lap̧te midh, in Borliegendem vorlüufig Beitrïge zu lies fern, weldhe fith wobl eignen bürften, bie $\mathfrak{A}$ ufmerffiam: feit auf biejen aheil ber Giejetggebung binzulenfen. Denn

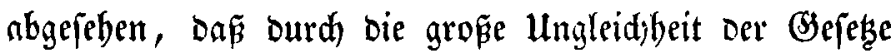
über ben $\mathfrak{B i e b g a n d e l}$ in ben veridjiedenen seutiden

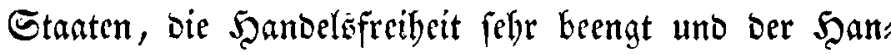
Del mit abieren febre fotwierig gemadjt ifî, fo fiften

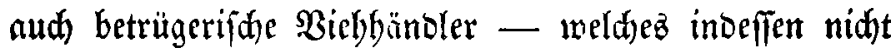
immer Suben finto - bei ben beftefenden mangelfaften gepestlidjen Beffimmungen, Dem unerfafrnen šnomanne

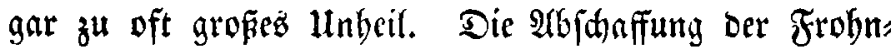

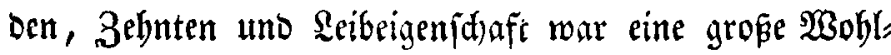


that für ben Ranomann; aber nidft minber wirb er ge: brüdt burdh ben abf(heulid)en Sd)adherbandel mit $\mathfrak{B i e f}$, uno eż Dürfte ebenjowobl an ber Zeit fenn, die sano;

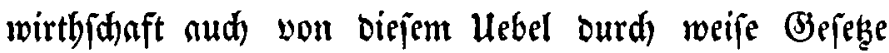
$\mathfrak{z u}^{\mathfrak{u}}$ befreien.

(S) iefen im December 1840.

Der Berfafier. 